\title{
Mean Residence Time Infinity Predicted by Intravascular Dose
}

National Cancer Institute

\section{Source}

National Cancer Institute. Mean Residence Time Infinity Predicted by Intravascular Dose. NCI Thesaurus. Code C121136.

The mean residence time (MRT) extrapolated to infinity for a substance administered by intravascular dosing, calculated using the predicted value of the last non-zero concentration. (CDISC) 